\title{
To Innovate or not to Innovate in the Didactic Second Language Scenario (and How) - that Is the Question?
}

Cristina CAlle-Martínez

Universidad Complutense de Madrid (Madrid)

$\mathrm{M}^{\mathrm{a}}$ Dolores CASTRILlo de Larreta-Azelain

Universidad Nacional de Educación a Distancia, UNED (Madrid)

Antonio PAREJA-Lora

Universidad Complutense de Madrid (Madrid)

Received: 25 April 2016 / Accepted: 26 April 2016

ISSN: 1697-7467

\section{INTRODUCTION}

The development and the evolution of digital information technologies have orchestrated the most significant advance in the history of second language didactics, in particular, in its online and/or distance modalities. This new era of Distance Foreign Language Learning, overrun by digital learning, social and gaming tools, has caused an authentic education revolution, qualified by significant researchers as disruptive. The rapid changes in the application of Information and Communication Technology (ICT) to education require carrying out urgently studies that analyse rigorously the potential benefits of this new digital media adoption, sometimes thoughtless and even unjustified, in the area of second language didactics.

In this monograph, relevant researchers working in the field provide a representative sampling of innovative experiences exploring new mobile, open and social models to enhance previous language learning practices. Regardless of whether it occurs autonomously, face-toface (F2F), distance-mediated (e.g. in Language Massive Open Online Courses - LMOOCs), or in hybrid courses, new digital affordances characterise the innovation in the didactic second language scenario. In this new language learning models, we need to reconsider the conceptual framework and the instructional model and reorganise or recreate content, materials, assignments and assessments (Dixon \& Fuchs, 2015). The subjects covered in this monograph revolve around the key issues in today's language teaching and learning models, namely Mobile-Assisted Language Learning (MALL), LMOOCs, assessment, and other hot topics and modalities of second language learning and/or teaching research (such as Content-and-Language Integrated Learning - CLIL).

It has been more than a decade since the first projects using mobile phones in language learning were launched (Chinnery, 2006). Mobile devices are most suitably designed for teaching/learning languages, because their features enable, for instance, communicative language practice, access to authentic content, task completion and portability (Jordano 
de la Torre, Castrillo de Larreta-Azelain \& Pareja-Lora, 2016). Lately, the introduction into language teaching of innovative mobile learning components (e.g., gamification strategies and new social and collaborative tools) has contributed to the creation of new learning scenarios. MALL provides the potential for personalizing the learning process, and making it spontaneous, informal and ubiquitous. Indeed, the new mobile scenario supports "concepts of learning such as ubiquitous-, augmented-, personalized-, online-, mixed reality-, context-sensitive-, informal-, and ambient learning and teaching." (Gholami \& Azarmi, 2012:1; see also Bárcena et al., 2015; Pareja Lora, Calle Martínez, \& Pomposo, 2015; Pareja Lora, Calle Martínez, \& Pomposo Yanes, 2016). This constant and sometimes dizzying implementation of new tools and strategies compels us to continue exploring and seeking appropriate theoretical frameworks and methodological models for an even better MALL (Kukulska-Hulme et al., 2011).

The need for a lifelong education, added to the high cost of higher education, has favoured the emergence and development of new learning models, based on open educational resources (OERs) and virtual environments. Massive Open Online Courses (MOOCs) and all their hybrid variants have opened a new way for massive informal learning. Furthermore, their synergies and utter compatibilities with regulated studies are palpable and, for this reason, many institutions have considered integrating them henceforth into formal learning grades. New business models are being considered, in which certifications and premium versions could cover expenses paid before by student tuition. The economic sustainability of higher education and other broader socio-economic and demographic factors seem to be decisive for the expansion of this new emerging educational model (Gašević et al., 2014).

One of the most significant changes regarding the instructional strategy of these new models of language teaching and learning is related to the new roles that teachers and students are forced to adopt. These new digital learning environments attract a new student profile. Thus, professionals and adults interact with young people - the traditional student profile. Teachers must take an eclectic and more flexible approach to teaching. Student-teacher boundaries are dissolving (Milstein, 2015) and this change in roles arise new challenges and didactic strategies (Castrillo de Larreta-Azelain, 2014). This links directly with one of the key trends of the last the Horizon Report (Johnson et al., 2015), namely integrating personalized learning, as these models and/or environments promote the development and implementation of personalized learning environments.

The digital features of this new second language scenario, like connectivity and functionality, enable new forms of language proficiency assessment. Innovative forms of measuring competences and credentialing are based on flexible assessment (see Table 1). 
Table 1. Categories of credentials (proficiency/competency assessment vs. flexiblelfixed amount of acquirement time) (Lang et al., 2014:142).

\begin{tabular}{|c|c|c|c|c|}
\hline & & & \multicolumn{2}{|c|}{ ASSESSMENT } \\
\hline & & & Proficiency & Competency \\
\hline \multirow{6}{*}{ TIME } & \multirow{3}{*}{ Fixed } & Demonstrates & Knowledge & Competency \\
\hline & & Uses & Tests or assignments & A range of assessments \\
\hline & & Occurs within & A set timeframe & A set timeframe \\
\hline & \multirow{3}{*}{ FLeXIBLe } & Demonstrates & Knowledge & Competency \\
\hline & & Uses & Tests or assignments & A range of assessments \\
\hline & & Occurs within & Student paced & Student paced \\
\hline
\end{tabular}

The new massive virtual learning environments require research to redefine the theoretical framework underpinning the new language teaching/learning models. The main areas to be covered in MOOC research are "i) student engagement and learning success, ii) MOOC design and curriculum, iii) self-regulated learning and social learning, iv) social network analysis and networked learning, and v) motivation, attitude and success criteria." (Gašević et al., 2014:163). Innovative research methods based on Learning Analytics (LA) focus on clearing up the key challenge of MOOCs, namely their low completion rates.

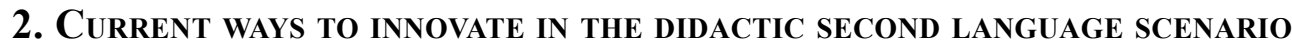

This special issue belongs to one of the richest areas of second language research and practice, the field focusing on the application of new technologies in English as a Second Language (ESL henceforth). As its title suggests, it examines this flourishing field by offering new findings in theory and practice and is aimed at both teachers and researchers in this area. Thus, the purpose of this special issue is to summon a collection of works that compile experiences and results from different points of view on the methodologies applied in the use of new technologies in ESL.

The special issue comprises ten articles. The first one, from García-Aretio and GarcíaBlanco, reviews different non-contact, teaching and learning methods with the aim of presenting a framework on which to build good teaching and learning practices. These good practices are linked to the acquisition of competences around the mastery of foreign languages. The work focuses on the latest models that have emerged on the basis of the integration of different media and resources that technological development has been encouraging. Among others, the variants presented are: teaching-learning by correspondence, distance teaching-learning with audio visual teaching aids and/or in virtual environments, blended learning, mobile learning, ubiquitous learning and Massive Open Online Courses (MOOCs). The authors remark the need and the importance of these distance modalities, emerged as a consequence of the needs that were not met by the campus-based system: (a) the need of a lifelong education, (b) the high cost of higher education, (c) the remoteness of some sectors of the population 
to the education centres, and (d) the ongoing widespread growth of universities, which has led to a decline of the teaching quality of these institutions.

The second article describes the production and efficiency of second language students as for vocabulary and oral skills acquisition, using modern technology for evaluation and the potential of social subtitling. In this sense, Cojocnean explores the factors that circumscribe students' low usage of MALL devices for the acquisition of English vocabulary. The study was done through a questionnaire and focus group discussions, where 1,239 Romanian participants assessed (i) their preferences for apps, (ii) the use of these devices as sources of entertainment, (iii) the grade of motivation in the use of this kind of technology for language learning, (iv) the absence of knowledge of the existence of apps designed for this purpose, (v) the need of a tutor supervision, and (vi) pedagogical and personal matters. The results of this study show that, although Romanian students have access to a wide range of digital devices to learn and practice English vocabulary, most of them use the least outstanding and those which offer a minor use of repetitions in the practice of vocabulary. To this we must join the fact of a lack of motivation and interest in learning such skill.

Then, Kétyi starts the third article by doing a review of the numerous research studies concerning the area of Mobile Assisted Language Learning (MALL) and showing the effectiveness of MALL in second and foreign language education. The author upholds in his article the combination of learning with educational games and game elements as an effective way to learn. Besides, backed by other studies about games for educational purposes proving that games are more interesting than conventional lesson instructions (Randel et al., 1992), Kétyi sustains that the concept of gamification (i.e., combining learning with games) could be thoughtfully examined in coming MALL undertakings. In his study, the author presents the results of three projects carried out between 2013 and 2015 on the effectiveness of two mobile applications (apps), namely Busuu and Lifeline, whose participants were students of the Budapest Business School. An in-depth analysis of the surveys carried out by the participants on the two apps revealed that the strengths are worth the weaknesses of Busuu and, hence, the suitability of Busuu for language learning.

The fourth article focuses on the potential of podcasts as a didactic resource for the development of oral skills in second language using mobile devices. In this regard, Bárcena presents in her study arguments for podcasting as a means for sharing contents of any kind to be listened or watched on a mobile device or any computing equipment. After an extensive review of the literature on the subject, the author analyses the application of podcasts to learning second languages and, in particular, the appropriateness of its use for the development of oral skills, both receptive and productive; and, within the latter, to aspects such as pronunciation, intonation and fluency. She reveals the advantages and achievements to date in an illustrative sample of research projects and educational experiences. Although podcasts were not originally made specifically for second language learners, can be used in second language classes to reinforce learning, promote listening comprehension and cultural competences and develop oral skills. In the last part of her article, the author predicts the increase in the coming years of exchange collaborative projects, joint development of podcasts among students from other parts of the world, combined into recent innovative and unprecedented teaching modalities, such as MOOCs.

In line with this, Ibáñez and Traxler explore in their article some pedagogical, linguistic and technical features of the MOOC and MALL prodigy. The authors show recent studies in 
the field of these two teaching modalities to later come to the key issue of the article, that is, the identification of a series of factors to be taken into account by language teachers in the design of an MOOC based on MALL, mainly drawn from technical, pedagogical and linguistic standards. Despite the wide range of courses on different aspects related to teaching instructions, blended learning or technology-enhanced teaching, limited are MALL-based LMOOCs. Some key aspects comprising linguistic, technical and pedagogical patterns should be taken into consideration when designing a MALL-based LMOOC: teacher beliefs and attitudes, the recipients, the cultural aspects of the course, interculturality and localization, the process of design and curating and, last but not least, as for MOOC pedagogy, an analysis of a heuristic approach that incorporates Open Educational Resources (OER) and teacher and language instruction among others in order to obtain greatest most enhanced learning.

Following this same line, Castaño, Maíz and Garay bring into focus in the sixth article two research tendencies in the near future classified according to pedagogical, technological and crucial criteria: the concern about hybrid MOOCs and about the students' learning results. The authors of this article delve into the research methodologies applied so far in MOOCs as for their technological, pedagogical and strategic perspectives, and suggest examining the educational values of actual MOOCs so as to fulfil more methodologically advanced studies. The authors highlight a number of meaningful weaknesses, such as (i) the real great variety of mixed MOOCs, which entails the presence of a fragmented field; and (ii) the inadequacy of the research methods used. Far from bringing negative effects on the advantageous development of MOOCs, these weaknesses led to a maturity phase, distinguished by an interest of researchers towards studies within a prominent scientific discipline and focused more on the students' learning than on the tasks carried out by them on the MOOC.

The following research is presented as part of a project (OPENPAU), conducted between February and March 2015 and funded by the Ministry of Education and Science. In particular, the work described by García-Laborda shows the preferences of a group of students in the second year of the Baccalaureate program towards the viability of using tablet (and desktop PCs) for English testing. The main aim of the study was to outline the students' replies to the two formats: the traditional written form and the new digital one. The innovative research presented here is a step forward to the use of modern technology, which facilitates educators a quick correction and, therefore, time-saving. But, despite the positive results encouraged by the students' feeling to the potential of tablet PCs as a means for delivery of standardized exams, there is still much to be done in this regard, since many limitations exist in education centres as for technological progress.

The next work focuses on the areas of Content-and-Language Integrated Learning (CLIL) and English as-a-Medium-of Instruction (EMI) as the two main alternative models for teaching in a bilingual environment within Tertiary Education. After a thorough review of the literature on the subject, the author presents an analysis of the academic achievement in students of first year who attended two bilingual subjects (namely, World Economic History and World Economy) in Economy and/or Business Management between 2010 and 2015. Towards this end, the author measured the impact on students' final grades of several factors, such as providing scaffolding and/or language support, designing student-led tasks, the previous student CEFR level, or using CLIL vs. using EMI. Doing this, Jiménez contributes to the discussion of how measuring grades quantifiably makes possible to evaluate the effectiveness of methodological interventions. More specifically, analysing the results 
of these impact measures, he found out that language adaptation, student-centeredness and independent learning should be encouraged within bilingual contexts.

The study of Talaván and Ávila-Cabrera provides some details about the results obtained from a previous social subtitling project conducted in 2014 by volunteer students at the Universidad Nacional de Educación a Distancia (UNED). The main purposes of the research were (i) to balance those previous investigations to shed more light on the capabilities of social subtitling of some UNED's audiovisual programs, in order to advance in productive research; and (ii) to make subtitling videos accessible to a greater number of users through UNED's virtual platform, aLF. The authors describe in their article the process of subtitling English video clips lacking subtitles in Spanish with the help of the subtitling editor Amara. Non-professional subtitling is becoming a trendy inclination that helps attain accessibility in audiovisual production within different settings, such as the university. This technique may be carried out as a didactic task by university students, who can subtitle materials created by their institutions while positively improving foreign language skills knowledge of their field of expertise.

The research that puts an end to this monograph focuses on the quality and assessment of oral production in English through online communication in the business environment. The author has previously carried out many research works in the business area as an in-company teacher and teacher-coordinator in several multinationals and other companies of Spain. She discovered that business environments mainly require oral communication and that this competence is the one most difficulty produced with quality and evaluated when promotions or projects are proposed. Here, Pomposo highlights the importance of verbal communication in the business world, since the only purpose of every business is to achieve its goal, but with a minimum of quality to cause a good impression. This is the reason why she does a thorough analysis on the factors involved in oral communication: morphosyntax, semantics, and prosody. In addition, she distinguishes the two perspectives from which oral communication must be measured: formal and functional. Finally, she also indicates that the objective of a qualified communication is not always fulfilled, especially if the means of communication is a technological tool.

\section{Conclusions}

Thus, all in all, this special issue provides an ample overview and a survey on the state of the art in second language teaching and/or learning, focusing mainly on a particular language, namely English as a Second Language. New modalities, methodologies and ways to teach this language are presented and analysed here, as well as the most innovative ways to learn it, and the means to enhance traditional learning environments by using new technologies and innovation. The purpose is clear: to provide new and better ways to learn (and practice) this and other languages. This is shown by the overwhelming number of terms referring to language learning modalities used all throughout the volume, such as autonomous learning, ubiquitous learning, self-regulated learning, blended learning, hybrid learning, informal lear- 
ning, distance learning, online learning, lifelong learning, (enhanced) face-to-face learning, augmented learning, personalized learning, context-sensitive learning, ambient learning, and social learning; or those more directly related to language learning, like Mobile-Assisted Language Learning (MALL) and Content-and-Language Integrated Learning (CLIL), for example. And it is also revealed by the number of new language (i.e., English) teaching modalities and techniques that are mentioned and described in its different articles, namely Language Massive Open Online Courses (LMOOCs), English as-a-Medium-of Instruction (EMI), gamification, podcasting, subtitling, and flexible or technology-enhanced assessment.

However, this special issue does not show, for example, how this degree of innovation already achieved in English teaching and learning is being attained or can be attained in other important, widely spoken and/or widespread (second) languages, such as French or Spanish. This remains an open question for future research.

\section{REFERENCES}

Bárcena, E., Read, T., Underwood, J., Obari, H., Cojocnean, D., Koyama, T., Pareja-Lora, A., Calle, C., Pomposo, L., Talaván, N., Ávila-Cabrera, J.J., Ibáñez, A., Vermeulen, A., Jordano, M., Arús-Hita, J., Rodríguez, P., Castrillo, M.D., Kétyi, A., Selwood, J., Gaved, M., and Kukulska-Hulme, A. (2015). "State of the art of language learning design using mobile technology: sample apps and some critical reflection”. In F. Helm, L. Bradley, M. Guarda, S. Thouësny (eds.), Critical CALL - Proceedings of the 2015 EUROCALL Conference, Padova, Italy. Dublin, Ireland: Research-publishing.net, 36-43.

Castrillo de Larreta-Azelain, M.D. (2014). "Language Teaching in MOOCs: the Integral Role of the Instructor", in E. Martín-Monje \& E. Bárcena (eds.), Language MOOCs. Providing Learning, Transcending Boundaries. Warsaw: De Gruyter Open, 67-90.

Chinnery, G.M. (2006). "Emerging Technologies. Going to the MALL: Mobile Assisted Language Learning", in Language Learning \& Technology, 10(1): 9-16.

Dixon, E. and Fuchs, C. (2015). "Face to Face, Online, or MOOC - How the Format Impacts Content, Objectives, Assignments, and Assessments", in E. Dixon \& M. Thomas (eds.), Researching Language Learner Interactions Online: From Social Media to MOOCs. Calico Monograph Series, 13: 89-105.

Gašević, D., Kovanović, V., Joksimović, S., and Siemens, G. (2014). "Where is research on massive open online courses headed? A data analysis of the MOOC Research Initiative", in G. Siemens, D. Gašević, \& Sh. Dawson (eds.), Preparing for the digital university: a review of the history and current state of distance, blended, and online learning. MRI. Bill and Melinda Gates Foundation, 161-198.

Gholami, J. and Azarmi, Gh. (2012). "An introduction to Mobile Assisted Language Learning", in International Journal of Management, IT and Engineering (IJMIE), 2(8): 1-9.

Jordano de la Torre, M., Castrillo de Larreta-Azelain, M. D., and Pareja-Lora, A. (2016). "El aprendizaje de lenguas extranjeras mediante tecnología móvil en el contexto de la educación a distancia y combinada", in RIED, Revista Iberoamericana de Educación a Distancia, 19 (1): 25-40.

Kukulska-Hulme, A. et al. (2011). "The genesis and development of mobile learning in Europe", in D. Parsons (ed.), Combining E-Learning and M-Learning: New Applications of Blended Educational Resources. Hershey, PA: Information Science Reference (an imprint of IGI Global), 151-177. 
Lang, Ch. et al. (2014). "The History and State of Credentialing and Assessment", in G. Siemens, D. Gašević, \& Sh. Dawson (eds.), Preparing for the digital university: a review of the history and current state of distance, blended, and online learning. MRI.Bill and Melinda Gates Foundation.

Milstein, D. (2015). "Pankake people, Throwaway Culture, and En Media Res Practices: A New Era of Distance Foreign Language Learning", in E. Dixon \& M. Thomas (eds.), Researching Language Learner Interactions Online: From Social Media to MOOCs. Calico Monograph Series, Vol. 13: 9-28.

Pareja Lora, A., Calle Martínez, C., and Pomposo, L. (2015). "BusinessApp: Una aplicación para el aprendizaje del inglés mediante dispositivos móviles en el campo de los negocios". En E-Aesla, 2015 (1) [Disponible en línea: http://cvc.cervantes.es/lengua/eaesla/pdf/01/19.pdf].

Pareja Lora, A., Calle Martínez, C., and Pomposo Yanes, L. (2016). "Aprendiendo a hacer presentaciones efectivas en inglés con BusinessApp". RIED. Revista Iberoamericana de Educación a Distancia, 19 (1), 41-61. DOI: http://dx.doi.org/10.5944/ried.19.1.14616.

Randel, J.M., Morris, B.A., Wetzel, C.D., and Whitehill, B.V. (1992). "The effectiveness of games for educational purposes: a review of recent research", in Simulation \& Gaming, 23(3): 261-276.

\section{Academic ANd professional profile of the guest editors}

\section{Cristina Calle Martínez}

Dr. Cristina Calle Martínez obtained a Ph.D. in English Philology from Universidad de Alcalá de Henares, on Aspects of Contrastive Rhetoric Applied to Scientific Texts (2004). She is a Professor at the English Philology Department of Universidad Complutense de Madrid (UCM) where she teaches mainly in the areas of English for Specific Purposes. She also teaches at the Facultad de Educación of Universidad Camilo José Cela (UCJC) in the Master of International Education and Bilingualism and in the Infant and Primary Education degree. Her teaching practice has received official recognition, which was awarded the $1^{\text {st }}$ Prize for Excellent Teaching Practices at UCJC. She has given many conferences and written articles and reviews in well-known educational journals. Her current main fields of research are mobile learning, language for specific purposes, teaching and learning through ICTs and bilingualism. She is a member of the ATLAS research group (Artificial Intelligence Techniques for Linguistic Applications) (ref: G87H31) where she has collaborated in several research projects, such as I-AGENT and SO-CALL-ME.

\section{$M^{a}$ Dolores Castrillo de Larreta-Azelain}

$\mathrm{M}^{\mathrm{a}}$ Dolores Castrillo holds a Senior Lecturer Position in the Department of Foreign Languages and Linguistics at UNED (Spanish University for Distance Learning), where she teaches mainly in the areas of German Studies and CALL (Computer Assisted Language Learning). Member of the ATLAS (Applying Technology to Languages) research group, her current research interests include Computer-Mediated Communication, Elearning, Mobile Assisted Language Learning (MALL), Open Educational Resources (OERs) and MOOCs (Massive Open Online Courses). Her publications include papers in indexed journals and book chapters both at national and international level. Her research and teaching practice have received official recognition, including her $\mathrm{PhD}$ thesis, which was awarded the Prize 
for Doctoral Excellence at UNED and she has recently won the first national prize to the best MOOC given by the Spanish Ministry of Education. She also won a national prize to the best OCW (Open Course Ware) given by the Spanish Ministry of Education in the first edition of such prize (2008).

\title{
Antonio Pareja-Lora
}

Antonio Pareja-Lora got a PhD. in Computer Science and Artificial Intelligence from the Universidad Politécnica de Madrid (UPM) in 2012. He is an Associate Professor (Profesor Contratado Doctor) at the Departamento de Sistemas Informáticos y Computación (DSIC - Computer Systems and Computation Department) of the Universidad Complutense de Madrid (UCM).

His research interests focus on natural language processing, linguistic and/or ontological annotation and the development of ontologies and linked data for the Humanities. In this line, he collaborated with the Ontology Engineering Group (OEG) of the UPM for more than eight years, in several European and national projects. Currently, he is a member of the ATLAS (Universidad Nacional de Educación a Distancia - UNED) and of the ILSA (UCM) research groups.

Dr. Pareja-Lora is the convenor of AENOR's CTN 191, an expert of ISO/TC 37, and also one of the officers of ACL SIGANN. His works have been published in several international journals, book chapters and conferences. He has served as reviewer for several international reputed conferences, such as ACL, COLING, IJCNLP, TKE or LREC and has some experience in organizing conferences, workshops and panels (e.g. TKE'2016 and LAW VII \& ID). His main publications can be found at his Google Scholar profile, https://scholar. google.es/citations?hl=en\&user=pm5VZUcAAAAJ.

\section{Addresses}

\author{
Cristina Calle-Martínez \\ Universidad Complutense de Madrid (Madrid) \\ Tel.: +34913946770 \\ Avda. Islas Filipinas, 3. C.P. 28003 Madrid, Spain \\ cristinacalle@filol.ucm.es \\ $\mathrm{M}^{\mathrm{a}}$ Dolores Castrillo de Larreta-Azelain \\ Universidad Nacional de Educación a Distancia, UNED (Madrid) \\ Tel.: +34913989236 \\ P. Senda del Rey, 7. C.P. 28040 Madrid, Spain \\ mcastrillo@flog.uned.es \\ Antonio Pareja-Lora \\ Universidad Complutense de Madrid (Madrid) \\ Tel.: +34913947578 \\ C/ Profesor José García Santesmases, 9. C.P. 28040 Madrid, Spain \\ aplora@ucm.es
}

